\title{
PENINGKATAN KESELAMATAN PELAYARAN MENCAPAI NOL KECELAKAAN KAPAL PENYEBERANGAN DI LINTAS KALI ADEM - PULAU SERIBU
}

\author{
Tarli, SE, MM \\ Dosen STTD \\ J1. Raya Setu No. 89, Bekasi \\ Telp./Fax : (021) 8254640
}

\author{
Sugita, SE, MM \\ Dosen STTD \\ J1. Raya Setu No. 89, Bekasi \\ Telp./Fax : (021) 8254640
}

\author{
Ir. Tri Yuli Andarau, ST, M.Sc \\ Dosen STTD \\ J1. Raya Setu No. 89, Bekasi \\ Telp./Fax : (021) 8254640
}

Bardi, SE, MM

Dosen STTD

J1. Raya Setu No. 89, Bekasi

Telp./Fax : (021) 8254640

\begin{abstract}
Kaliadem Jakarta ferry port serves crossing from Jakarta to several ports on Seribu Island as a tourist destination for the DKI Jakarta province. Along with this, the level of service provided by Kaliadem facilities and ferry ports is still inadequate, this can be seen from the weak supervision of the transportation services of people on ships related to the safety and security requirements of transport in the waters through adherence to the fulfillment of ship capacity, the lack of training to increase and maintain the skills and skills of crew members and the lack of discipline of shipping service users to the importance of ship shipping safety and the lack of maintenance of ships and all auxiliary equipment and radio communication equipment on board
\end{abstract}

Keyword: Port of diversion, Kali Adem - Pulau Seribu, safety

\begin{abstract}
ABSTRAKSI
Pelabuhan penyeberangan Kaliadem Jakarta melayani lintas penyeberangan dari Jakarta ke beberapa pelabuhan yang ada di Pulau Seribu sebagai daerah tujuan wisata bagi propinsi DKI Jakarta, Seiring dengan hal tersebut sejauh ini tingkat pelayanan yang diberikan oleh operator sarana dan pelabuhan penyeberangan kaliadem masih belum memadai, hal ini terlihat dari lemahnya pengawasan pelayanan angkutan orang di kapal yang terkait dengan persyaratan keselamatan dan keamanan angkutan di perairan melalui ketaatan terhadap pemenuhan kapasitas muat kapal, Kurangnya pelatihan untuk menambah dan mempertahankan kecakapan dan ketrampilan anak buah kapal dan lemahnya disiplin dari pengguna jasa pelayaran terhadap pentingnya keselamatan pelayaran kapal serta kurangnya perawatan kapal dan semua perlengkapan peralatan penolong dan peralatan komunikasi radio di kapal
\end{abstract}

Keyword : Pelabuhan penyebranagan,kali adem - pulau seribu, keselamatan 


\section{PE N D A U L U A N}

Pelabuhan penyeberangan Kaliadem Jakarta melayani lintas penyeberangan dari Jakarta ke beberapa pelabuhan yang ada di Pulau Seribu. Seiring dengan hal tersebut sejauh ini tingkat pelayanan yang diberikan oleh operator sarana dan pelabuhan penyeberangan kaliadem masih belum memadai,

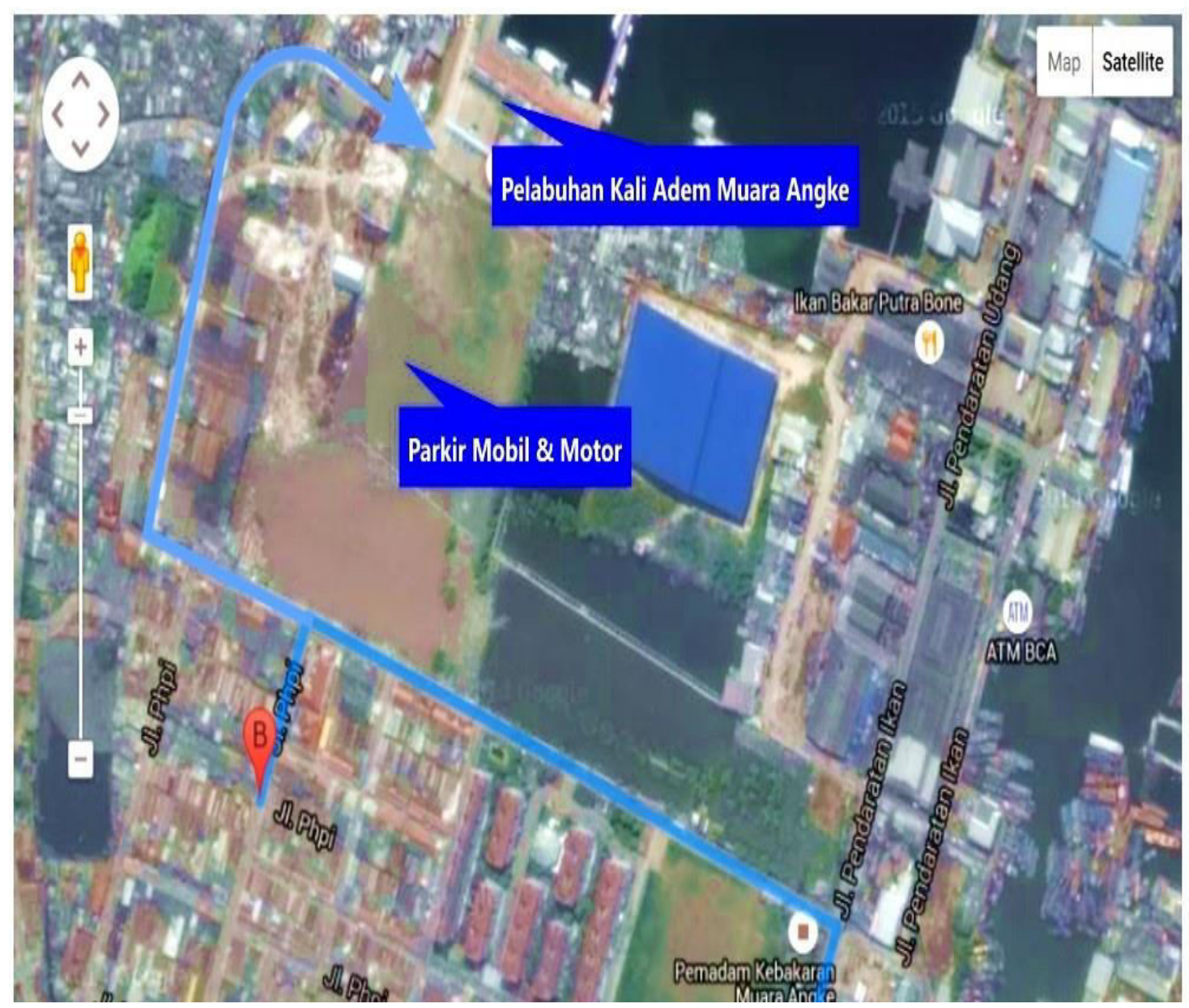

\section{GAMBAR 1,}

Layout Pelabuhan Kali Adem

\section{A. IDENTIFIKASI MASALAH}

1. Terjadinya kecelakaan kapal pada saat melakukan pelayaran ke pulau seribu dimana kapal baru keluar dari kolam pelabuhan mengalami kecelakaan yakni dengan terbakarnya kapal yang diperkirakan karena kurang siapnya peralatan dan terampilnya awak kapal tersebut, 
mengakibatkan kecelakaan menjadi sangat serius karena banyak korban tidak terselamatkan.

2. Lemahnya pengawasan dari institusi pelayaran terkait dan kurang tanggapnya perusahaan pelayaran terutama dalam hal ketersediaan fasilitas keselamatan dan ketaatan terhadap aturan yang terkait dengan Fasilitas keselamatan pelayaran

3. Kurangnya pelatihan untuk menambah dan mempertahankan kecakapan dan ketrampilan anak buah kapal dan lemahnya disiplin dari pengguna jasa pelayaran terhadap pentingnya keselamatan pelayaran kapal serta kurangnya perawatan kapal dan semua perlengkapan peralatan penolong dan peralatan komunikasi radio di kapal.

4. Lemahnya pengawasan instansi pemerintah dan perusahaan pelayaran terkait dengan jumlah penumpang kapal yang melebihi kapasitas muat kapal sesuai ketentuan yang dikeluarkan oleh IMO..

\section{B. BATASAN MASALAH}

Dari hasil identifikasi masalah tersebut di atas dan terbatasnya waktu pelaksanaan survey serta dana yang tersedia, maka untuk mempermudah penyelesaian penelitian ini permasalahan dibatasi hanya pada pemenuhan kelaik lautan kapal yang terkait dengan ketaatan terhadap pemenuhan kapasitas muat kapal yang telah di syaratkan ditetapkan oleh IMO di pelabuhan penyeberangan Kali Adem Jakarta, adapun obyek penelitian tidak seluruh kapal penumpang yang berlabuh di pelabuhan Kali Adem namun hanya tiga kapal yaitu KM Kerapu, KM Kurnia dan KM Jelajah

\section{E T O D O L O G I P E N E L I T I A N}

Secara rinci dapat dijelaskan sebagai berikut :

1. Identifikasi masalah

Pada tahapan ini akan didapat berbagai masalah dari wilayah penelitian yang selanjutnya untuk mempermudah penyelesaian penelitian dibuat perumusan masalah yang diambil dari batasan permasalahan yang akan diteliti.

2. Pengumpulan data 
Pengumpulan data ini meliputi pengumpulan data sekunder yang didapat dari instansi terkait seperti Dinas Perhubungan Pemda DKI Jaya, Ditjen Perhubungan Darat Kementrian Perhubungan dan stakeholder. Sedangkan data primer diambil langsung melalui survey dilapangan yakni kapal capat KM Kerapu, KM Kurnia dan KM Jelajah di Pelabuhan Kaliadem Jakarta Utara .

3. Pengolahan data

Setelah dilakukan pengumpulan data maka dilakukan analisa pengolahan data melalui analisa deskriptif sehingga mendapatkan hasil yang tepat dan dapat dipercaya .

4. Keluaran (output)

Pada tahap ini merupakan tahap akhir yang meliputi tindak lanjut dari hasil analisa data yang selanjutnya dituangkan dalam bentuk kesimpulan, saranan rekomendasi

\section{ANALISA DAN PEMBAHASAN}

\section{A. ANALISA KETAATAN PEMUATAN KAPAL EKSISTING}

Dari hasil survey diperoleh data jumlah kapasitas muat kapal, jumlah penumpang naik dari Pelabuhan Kali Adem menuju pelabuhan-pelabuhan di pulau seribu dan jumlah penumpang yang turun di pelabuhan Kaliadem dari pelabuhan-pelabuhan di pulau seribu, sehingga dapat dihitung persentase perbandingan antara jumlah penumpang naik di pelabuhan Kaliadem ke pelabuhan-pelabuhan pulau seribu dan turun di pelabuhan Kaliadem dari pelabuhan-pelabuhan Pulau Seribu dibandingkan dengan kapasitas muat kapal untuk kapal KM Kerapu, KM Kurnia dan KM Jelajah untuk hari senin sampai dengan hari minggu pertama dan ketiga bulan Agustus 2018 sebagaimana TABEL I.1, TABEL I.2, TABEL II.1, TABEL II,2, TABEL III.1, dan TABEL II.2 :

1. KM KERAPU

TABEL I.1, Survey KM. KERAPU minggu pertama bulan Agustus 2018

\begin{tabular}{|l|c|c|c|c|c|}
\hline JADWAL & $\begin{array}{c}\text { KAPASITA } \\
\text { S MUAT }\end{array}$ & $\begin{array}{c}\text { PENUMPAN } \\
\text { G NAIK }\end{array}$ & $\begin{array}{c}\text { PENUMPAN } \\
\text { G TURUN }\end{array}$ & $\begin{array}{c}\% \\
\text { PENUMPAN } \\
\text { G NAIK }\end{array}$ & $\begin{array}{c}\% \\
\text { PENUMPAN } \\
\text { G TURUN }\end{array}$ \\
\hline SENIN & 22 & 22 & 23 & 100 & 105 \\
SELASA & 22 & 21 & 22 & 95 & 100 \\
RABU & 22 & 20 & 20 & 91 & 91 \\
\hline
\end{tabular}




\begin{tabular}{|l|l|l|l|c|c|}
\hline KAMIS & 22 & 19 & 20 & 86 & 91 \\
JUMAT & 22 & 22 & 21 & 100 & 95 \\
SABTU & 22 & 25 & 23 & 114 & 105 \\
MINGG & 22 & 23 & 24 & 105 & 109 \\
U & & & & & \\
\hline
\end{tabular}

TABEL I.2, Survey KM KERAPU minggu ketiga bulan Agustus 2018

\begin{tabular}{|l|c|c|c|c|c|}
\hline JADWAL & $\begin{array}{c}\text { KAPASIT } \\
\text { AS MUAT }\end{array}$ & $\begin{array}{c}\text { PENUMPAN } \\
\text { G NAIK }\end{array}$ & $\begin{array}{c}\text { PENUMPAN } \\
\text { G TURUN }\end{array}$ & $\begin{array}{c}\% \\
\text { PENUMPAN } \\
\text { G NAIK }\end{array}$ & $\begin{array}{c}\% \\
\text { PENUMPAN } \\
\text { G TURUN }\end{array}$ \\
\hline SENIN & 22 & 21 & 22 & 100 & 104 \\
SELASA & 22 & 20 & 21 & 95 & 96 \\
RABU & 22 & 22 & 18 & 90 & 82 \\
KAMIS & 22 & 21 & 19 & 86 & 86 \\
JUMAT & 22 & 22 & 21 & 100 & 95 \\
SABTU & 22 & 22 & 22 & 113 & 100 \\
MINGG & 22 & 23 & 24 & 113 & 109 \\
U & & & & \\
\hline
\end{tabular}

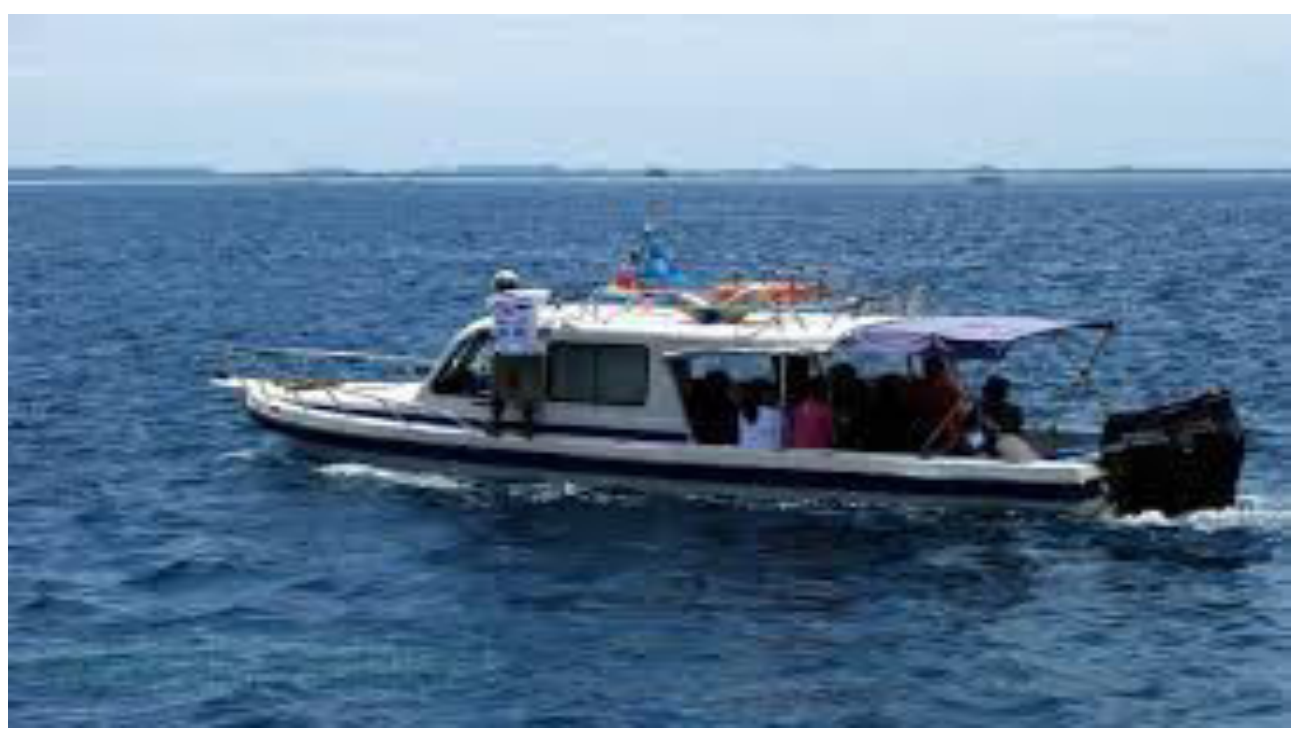

GAMBAR 3, Kapal KM Kerapu Sedang Berlayar

2. KM.KURNIA,

Tabel II.1, survey KM Kurnia minggu pertama agustus 2018

\begin{tabular}{|c|c|c|c|c|c|}
\hline JADWAL & $\begin{array}{c}\text { KAPASI } \\
\text { TAS } \\
\text { MUAT }\end{array}$ & $\begin{array}{c}\text { PENUMPAN } \\
\text { G NAIK }\end{array}$ & $\begin{array}{c}\text { PENUMPAN } \\
\text { G TURUN }\end{array}$ & $\begin{array}{c}\% \\
\text { PENUMPANG } \\
\text { NAIK }\end{array}$ & $\begin{array}{c}\% \\
\text { PENUMPANG } \\
\text { TURUN }\end{array}$ \\
\hline
\end{tabular}




\begin{tabular}{|l|c|c|c|c|c|}
\hline SENIN & 100 & 98 & 112 & 98 & 112 \\
SELAS & 100 & 87 & 85 & 87 & 85 \\
A & 100 & 96 & 78 & 96 & 78 \\
RABU & 100 & 85 & 83 & 85 & 83 \\
KAMIS & 100 & 105 & 80 & 105 & 80 \\
JUMAT & 100 & 120 & 95 & 120 & 95 \\
SABTU & 100 & 98 & 121 & 98 & 121 \\
& & & & & \\
MINGGU & & & & & \\
\hline
\end{tabular}

Tabel II.2, survey KM Kurnia minggu pertama agustus 2018

\begin{tabular}{|l|c|c|c|c|c|}
\hline JADWAL & $\begin{array}{c}\text { KAPASITA } \\
\text { S MUAT }\end{array}$ & $\begin{array}{c}\text { PENUMPAN } \\
\text { G NAIK }\end{array}$ & $\begin{array}{c}\text { PENUMPAN } \\
\text { G TURUN }\end{array}$ & $\begin{array}{c}\% \\
\text { PENUMPAN } \\
\text { G NAIK }\end{array}$ & $\begin{array}{c}\% \\
\text { PENUMPAN } \\
\text { G TURUN }\end{array}$ \\
\hline SENIN & 100 & 82 & 121 & 82 & \\
SELAS & 100 & 78 & 82 & 78 & 82 \\
A & 100 & 90 & 79 & 90 & 79 \\
RABU & 100 & 86 & 87 & 86 & 87 \\
KAMIS & 100 & 125 & 84 & 125 & 84 \\
JUMAT & 100 & 128 & 117 & 128 & 128 \\
SABTU & 100 & 95 & 124 & 95 & 124 \\
MINGGU & & & & & \\
\hline
\end{tabular}

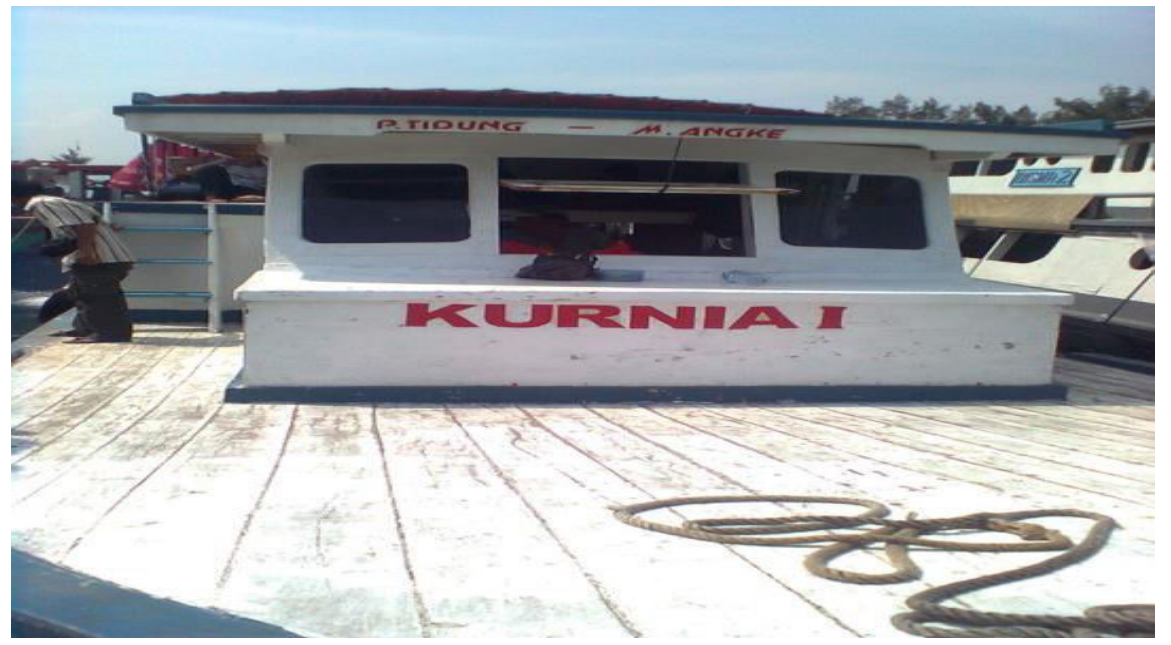

GAMBAR 4, Kapal KM Kurnia Sedang Sandar

3. KM.JELAJAH,

TABEL III.1, survey Kapal KM Jelajah minggu I bulan agustus 2018

\begin{tabular}{|c|c|c|c|c|c|}
\hline JADWAL & $\begin{array}{c}\text { KAPASITA } \\
\text { S MUAT }\end{array}$ & $\begin{array}{c}\text { PENUMPAN } \\
\text { G NAIK }\end{array}$ & $\begin{array}{c}\text { PENUMPAN } \\
\text { G TURUN }\end{array}$ & $\begin{array}{c}\% \\
\text { PENUMPAN } \\
\text { G NAIK }\end{array}$ & $\begin{array}{c}\% \\
\text { PENUMPAN } \\
\text { G TURUN }\end{array}$ \\
\hline SENIN & 100 & 85 & 118 & 85 & 118 \\
SELAS & 100 & 92 & 92 & 92 & 92 \\
\hline
\end{tabular}




\begin{tabular}{|l|c|c|c|c|c|}
\hline A & 100 & 89 & 89 & 89 & 89 \\
RABU & 100 & 93 & 93 & 93 & 93 \\
KAMIS & 100 & 94 & 94 & 94 & 94 \\
JUMAT & 100 & 112 & 112 & 112 & 112 \\
SABTU & 100 & 98 & 124 & 98 & 98 \\
& & & & & \\
MINGGU & & & & & \\
\hline
\end{tabular}

TABEL III.2, survey Kapal KM Jelajah minggu III bulan Agustus 2018

\begin{tabular}{|l|c|c|c|c|c|}
\hline Jadwal & $\begin{array}{c}\text { KAPASIT } \\
\text { AS } \\
\text { MUAT }\end{array}$ & $\begin{array}{c}\text { PENUMPAN } \\
\text { G NAIK }\end{array}$ & $\begin{array}{c}\text { PENUMPAN } \\
\text { G TURUN }\end{array}$ & $\begin{array}{c}\% \\
\text { PENUMPAN } \\
\text { G NAIK }\end{array}$ & $\begin{array}{c}\% \text { PENUMPANG } \\
\text { TURUN }\end{array}$ \\
\hline SENIN & 100 & 98 & 84 & 98 & 84 \\
SELASA & 100 & 87 & 91 & 87 & 91 \\
RABU & 100 & 90 & 87 & 90 & 87 \\
KAMIS & 100 & 88 & 89 & 88 & 89 \\
JUMAT & 100 & 119 & 91 & 119 & 91 \\
SABTU & 100 & 122 & 115 & 122 & 115 \\
MINGGU & 100 & 92 & 122 & 92 & 92 \\
\hline
\end{tabular}

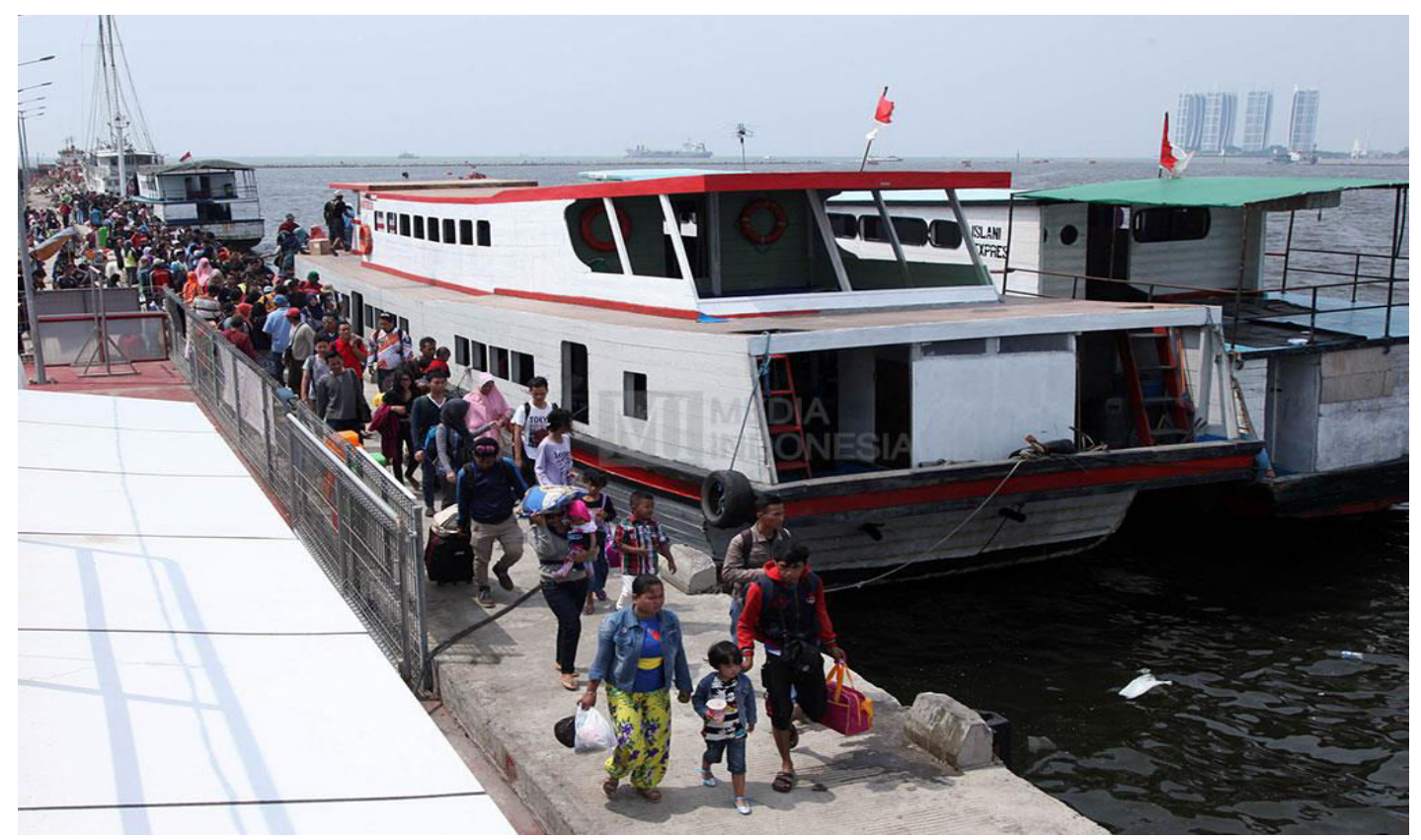

GAMBAR 5, Kapal KM Jelajah Sedang Sandar

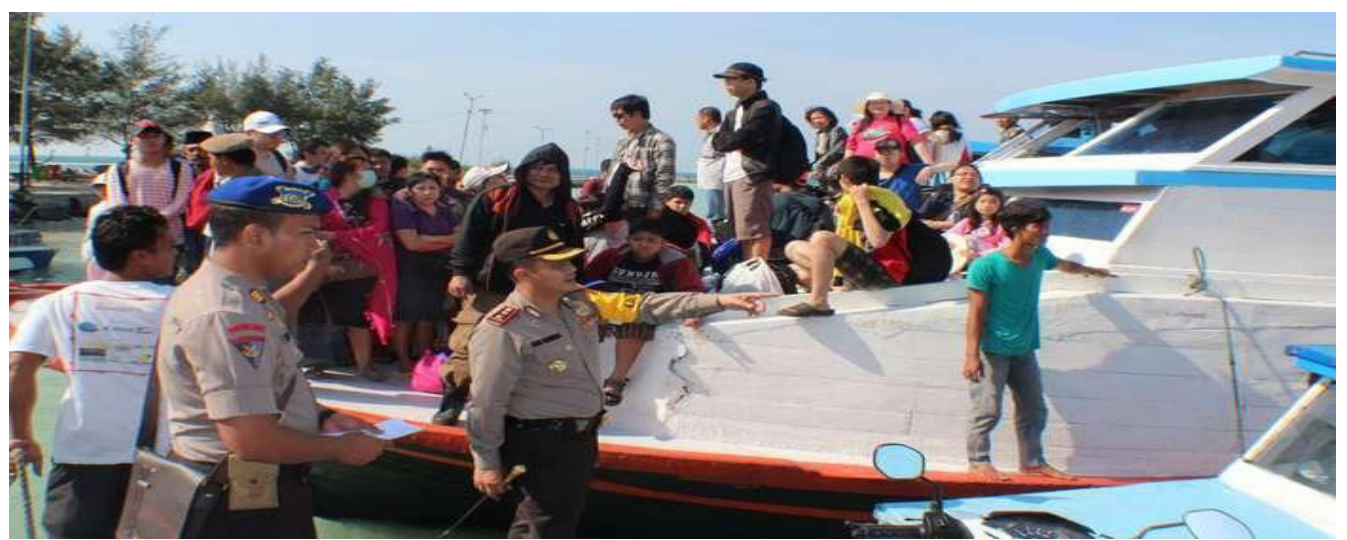

GAMBAR 6, Km. Jelajah Kelebihan Penumpang. 
Data penumpang naik di pelabuhan keberangkatan Kaliadem ke pelabuhanpelabuhan tujuan di Pulau Seribu dan penumpang turun di pelabuhan Kaliadem dari pelabuhan-pelabuhan di Pulau Seribu untuk kapal KM.KERAPU, KM.KURNIA dan KM. JELAJAH yang beroperasi menyeberangkan orang dan barang dari dan ke pelabuhan Kaliadem serta ke pulau pulau yang berada di Pulau Seribu tersebut dalam pelaksanaannya masih tedapat adanya penyimpangan terhadap fakftor garis muat yakni pelanggaran garis muat kapal akibat dari kelebihan kapasitas muat yang dikarenakan pengguna jasa penumpang lebih senang menggunakan kapal KM. KERAPU karena disamping kapal tersebut adalah kapal baru yang mempunyai kecepatan tinggi dengan waktu tempuh sekitar 1 jam 30 menit. Sedang untuk kapal KM.KURNIA dan KM.JELAJAH membutuhkan waktu pelayaran 2- 3 jam tergantung dari situasi hidrografi pelayaran dari dan ke pulau seribu untuk sampai di pulau pramuka di kepulauan seribu, namun demikian kapal kapal tersebut yakni KM.KURNIA dan KM.JELAJAH merupakan kapal yang nyaman dan cukup besar kapasitas muatnya antara 100 - 125 0rang dengan bobot kapal 75 GT sehingga banyak penumpang yang berminat untuk menggunakan kapal tersebut, KM.JELAJAH DAN KM.KURNIA yang mempunyai bobot 75 GT dengan lebar kapal 4 meter dan panjang sekitar 20 sampai dengan 25 meter, mempunyai kapasitas muat sekitar 100 orang sementara itu KM.KERAPU yang mempunyai bobot dibawah 35 GT dan mempunyai kecepatan yang cukup tinggi dengan lebar kapal hanya tiga meter dan panjang 12 meter dengan jumlah tempat duduk tersedia hanya 20 penumpang, sedangkan penyimpangan yang dilakukan adalah pemuatan penumpang melebihi kapasitas muat kapal, akibat kelebihan penumpang dari kapal-kapal tersebut di atas seharusnya tidak diperbolehkan baik dalam kondisi diam dan bergerak karena akan mengakibatkan tingkat stabilitas kapal menjadi stabilitas negative .

\section{B. ANALISA PERALATAN PENUNJANG KESELAMATAN PELAYARAN 1. KAPAL KM KERAPU}

Ketersediaan peralatan penunjang keselamatan pelayaran seperti life jacket untuk keselamatan penumpang dan anak buah kapal untuk KM 
KERAPU sudah cukup memadai yakni berjumlah 30 buah life jacket sedang peralatan komunikasi dengan radio SSB dan sarana bantu navigasi pelayaran juga terlihat masIh berfungsi dengan baik dan secara optimal. Dan awak kapal juga terlatih dalam hal ketrampilan penanganan dan pencegahan kecelakaan kapal di laut yang dibuktikan dengan Laporan dari perusaahaan kapal cepat rersebut yaitu telah dilakukan duakali pelatihan dan ketrampilan pencegahan dan penanganan kecelakaan dilaut sesuai amandemen peningkatan keselamatan melalui ISM CODE yang terkait dengan SOLAS

\section{KAPAL KURNIA}

Ketersediaan peralatan penunjang keselamatan pelayaran seperti life jacket untuk keselamatan penumpang dan anak buah kapal untuk KM kurnia sudah cukup memadai yakni berjumlah 120 buah life jacket yang berfungsi dengan baik. sedang peralatan komunikasi dengan radio SSB dan navigasi pelayaran juga terlihat masih berfungsi dengan baik dan dapat dioperasikan secara optimal. sedang awak kapal juga telah terlatih dalam hal ketrampilan penanganan dan pencegahan kecelakaan kapal di laut yang dibuktikan dengan laporan dari perusahaan kapal penumpang tersebut bahwa telah dilakukan pelatihan ketrampilan penanganan dan pencegahan kecelakaan dilaut selama empat kali dalam setahun sesuai dengan amandemen manajemen peningkatan keselamatan pelayaran ISM CODE yang terkait dengan SOLAS

\section{KAPAL JELAJAH}

Ketersediaan peralatan penunjang keselamatan pelayaran seperti life jacket untuk keselamatan penumpang dan anak buah kapal untuk KM JELAJAH sudah cukup memadai yakni berjumlah 125 buah life jacket yang berfungsi dengan baik . sedang peralatan komunikasi dengan radio SSB dan navigasi pelayaran masih terlihat baik dan berfungsi normal serta dapat dioperasikan secara optimal. sedang awak kapal juga sudah terlatih dalam hal ketrampilan penanganan dan pencegahan kecelakaan kapal di laut yang dibuktikan dengan laporan dan informasi dari petugas 
pelabuhan dan anak buah kapal bahwa perusahaan kapal tersebut melakukan pelatihan sebanyak dua kali dalam setahun sesuai dengan amandemen manajemen peningkatan keselamatan

\section{A. KESIMPULAN}

Berdasar hasil analisis dan evaluasi yang dilakukan di lokasi pelabuhan muara angke Kali Adem Jakarta Utara maka diperoleh kesimpulan sebagai berikut :

1. Persyaratan pelayanan angkutan penyeberangan sudah dipenuhi khusus untuk angkutan penumpang yaitu menggunakan Kapal KM. Kerapu, KM. Kunia dan KM. Jelajah dengan jenis LIFT ON - LIFT OF dan relatif tidak melebihi daya angkut serta penempatan posisi barang bawaan yang tepat yang sesuai dengan SOP sehingga tidak akan mengakibatkan kurangnya stabilitas dari kapal tersebut .

2. Waktu pelayanan naik dan turun penumpang yang dilakukan di dermaga kurang baik karena waktu naik dan turun masih cukup lama berkisar antara $50-85$ menit

3. Dari hasil pengamatan dilapangan operator pelabuhan kali adem belum memberikan waktu batas maksimum untuk naik dan turun penumpang sedang untuk barang bawaan sudah ada pembatasan yaitu satu penumpang hanya boleh menbawa barang bawaan seberat $20 \mathrm{~kg}$ saja, sedang untuk pengurusan dokumen pelayaran untuk pemberangkatan kapal masih bervariasi antara 30 sampai dengan 60 menit hal ini tergantung dari kesiapan dokumen dan kesiapan dari ketersediaan fasilitas peralatan keselamatan dan keamanan kapal yang harus dalam kondisi prima.

4. Jumlah kapal beroperasi di pelabuhan kali adem sementara berjumlah 48 kapal tradisional dengan badan kapal terbuat dari kayu sampai dengan fiberglas dengan pembuatan kapal rata rata dibawah tahun 2005 dan hanya sebagian yang berusia muda seperti kapal kerapu yang berjumlah 10 buah dan beberapa buah kapal kurnia dan kapal Jelajah dengan tahun pembuatan 2016 .

5. Sumber Daya Manusia tersedia untuk melayani operasi kapal dan pelabuhan di Pelabuhan muara angke kali adem sudah cukup memadai 
yakni masing - masing kapal sudah menyiapkan 3 s/d 5 orang di darat untuk mengatur naik dan turun penumpang ke kapal

6. Bila melihat ketersediaan seluruh fasilitas baik sarana dan prasarana di pelabuhan kali adem sudah cukup memadai, namun perlu dilakukan antisipasi dimasa yang akan datang yakni diperkirakan akan terjadi kenaikan jumlah penumpang yang secara otomatis akan menambah kapal baik dari segi jumlah dan kapasitas muat kapal yang pada saat ini tidak memungkinkan kapal yang lebih besar untuk merapat di pelabuhan kali adem, karena kondisi kolam yang tersedia hanya mempunyai kedalaman $200 \mathrm{~cm}$ saja

\section{B. SARAN}

Dari kesimpulan tersebut di atas pelayanan di pelabuhan kali adem agar dapat berjalan optimal, maka disarankan agar :

1. Perlu dilakukan pengelompokan jenis kapal sesuai kapasitas muat dan perlu diberikan pula batasan waktu untuk naik dan turun penumpang sehingga mudah untuk melakukan KONTROL terhadap kapasitas muat dari seluruh armada kapal yang beroperasi di pelabuhan muara anggke kali adem Jakarta utara

2. Untuk mencegah dan mengantisipasi pertumbuhan angkutan penumpang dan daya tampung barang bawaan di kapal yang diperkirakan akan mengakibatkan terjadinya antrean dimasa yang akan datang ,perlu ditambah dermaga panjang dermaga dengan daya dukung yang memadai dan memperdalam kolam pelabuhan menjadi $500 \mathrm{~cm}$ sehingga dapat disandari kapal dengan bobot sampai dengan 1000 GRT.

3. Perlu dilakukan peremajaan dan peningkatan bobot kapal untuk menambah kapasitas angkut selain itu Perlu pula dibangun fasilitas terminal pemberangkatan dan lapangan parkir di dalam lokasi pelabuhan untuk mengantisipasi jumlah kendaraan pengantar yang diperkirakan akan terus meningkat.

4. Peningkatan keahlian dan ketrampilan sumber daya manusia operator kapal dan pelabuhan, serta penambahan SDM profesional untuk mengimbangi peningkatan pelayanan fasilitas sarana dan prasarana dimasa datang . 
Undang-Undang Republik Indonesia No. 17 Tahun 2007 Tentang Pelayaran , peraturan Pemerintah No 72 tahun 2009 tentang lalu lintas angkutan penyeberangan , peraturan pemerintah No 50 tahun 2009 tentang penyelenggaraan pelabuhan penyeberangan

, Peraturan pemerintah no 5 tahun 2010 tentang kenavigasian , transportasi penyeberangan oleh Iskandar Abubakar pengantar teknik dan perencanaan transportasi oleh Edward k Morlok Master plan PT.ASDP MERAK 2017 